Research Article

\title{
Selective Oxidation of Styrene to Benzaldehyde by Co-Ag Codoped ZnO Catalyst and $\mathrm{H}_{2} \mathrm{O}_{2}$ as Oxidant
}

\author{
Abderrazak Aberkouks, ${ }^{1}$ Ayoub Abdelkader Mekkaoui (D), ${ }^{1,2}$ Brahim Boualy, ${ }^{2}$ \\ Soufiane El Houssame, ${ }^{2}$ Mustapha Ait Ali, ${ }^{1}$ and Larbi El Firdoussi iD $^{1}$ \\ ${ }^{1}$ Laboratoire de Chimie de Coordination et de Catalyse, Département de Chimie, Faculté des Sciences Semlalia, BP 2390, 40001 \\ Marrakech, Morocco \\ ${ }^{2}$ Laboratoire de Chimie et Modélisation Mathématique, Faculté Polydisciplinaire de Khouribga, Université Hassan 1er, BP 145, \\ 25000 Khouribga, Morocco
}

Correspondence should be addressed to Larbi El Firdoussi; elfirdoussi@uca.ac.ma

Received 7 November 2017; Revised 20 February 2018; Accepted 25 March 2018; Published 24 April 2018

Academic Editor: Marco Cannas

Copyright ( 12018 Abderrazak Aberkouks et al. This is an open access article distributed under the Creative Commons Attribution License, which permits unrestricted use, distribution, and reproduction in any medium, provided the original work is properly cited.

\begin{abstract}
Various ratio of Co-Ag supported on $\mathrm{ZnO}$ have been evaluated in the selective catalytic oxidation of styrene to benzaldehyde, using $\mathrm{H}_{2} \mathrm{O}_{2}$ as an oxidant. The catalysts were prepared by a sol-gel process and were characterized using XRD, FT-IR, TG-DTG, $\mathrm{BET}$, and SEM/EDX. The performance of the prepared catalyst was investigated under different parameters such as solvent, temperature, substrate/oxidant molar ratios, reaction time, and doping percent. The $\mathrm{Zn}_{1-x-y} \mathrm{Ag}_{x} \mathrm{Co}_{y} \mathrm{O}$ catalysts exhibit a good activity and a high selectivity towards benzaldehyde (95\%) with the formation of only $5 \%$ of acetophenone.
\end{abstract}

\section{Introduction}

Benzaldehyde is an important intermediate in the industrial fine chemical synthesis for fragrances, flavorings, pharmaceuticals, and in the organic synthesis $[1,2]$. Conventional preparation of benzaldehyde is based on the hydrolysis of benzyl chloride, and it can be obtained as an intermediate of the oxidation of toluene to benzoic acid $[3,4]$. This process was not environmentally friendly because of using organic solvents and producing traces of chlorine [5]. The development of recyclable catalysts, to simply separate from the reaction mixture, has attracted an economic and ecological interest [6]. In this context, there are two categories of catalysts: transition metal immobilized or constituted molecular sieves, such as NbCo-MCM-41 [7], VSB-5 [8], and Co-ZSM-5 [9], and application of metal oxides or complexes, such as $\mathrm{Mg}_{x} \mathrm{Fe}_{3-x} \mathrm{O}_{4}[1]$ and $\mathrm{TiO}_{2} / \mathrm{SiO}_{2}$ [10]. Recently, Long et al. [11] have developed magnetic microparticles immobilizing palladium acetate as heterogeneous coordination catalysts for selective oxidation of styrene allowing mainly to prepare acetophenone. Earlier, it was shown that in the presence of activated carbon $(\mathrm{AC})$ and $\mathrm{H}_{2} \mathrm{O}_{2}$ as the oxidant, the styrene was selectively converted to benzaldehyde [12].

The main objective of this work was the preparation of heterogeneous supported catalysts $\left(\mathrm{Zn}_{1-x-y} \mathrm{Ag}_{x} \mathrm{Co}_{y} \mathrm{O}\right)$ by a sol-gel method and their evaluation in the oxidation of styrene to benzaldehyde (supplementary data 1).

\section{Experimental Details}

2.1. Materials. Zinc acetate dihydrate $\left(\mathrm{Zn}\left(\mathrm{CH}_{3} \mathrm{COO}\right)_{2} \cdot 2 \mathrm{H}_{2} \mathrm{O}\right)$, cobalt nitrate hexahydrate $\left(\mathrm{Co}\left(\mathrm{NO}_{3}\right)_{2} \cdot 6 \mathrm{H}_{2} \mathrm{O}\right)$, silver nitrate $\left(\mathrm{Ag}\left(\mathrm{NO}_{3}\right)\right)$, citric acid $\left(\mathrm{HOC}(\mathrm{COOH})\left(\mathrm{CH}_{2} \mathrm{COOH}\right)_{2}\right)$, hydrogen peroxide $\left(\mathrm{H}_{2} \mathrm{O}_{2} 30 \mathrm{wt} . \%\right)$, ethanol, styrene, acetonitrile, acetone, and methanol were purchased from SigmaAldrich chemical reagent grade and used as received.

2.2. Characterization. Thermogravimetric analysis (TGA) was recorded on a TA Instrument Q500 apparatus in flowing air at a heating rate of $10^{\circ} \mathrm{C} \cdot \mathrm{min}^{-1}$. BET specific surface areas and average pore diameter of the prepared catalyst were 


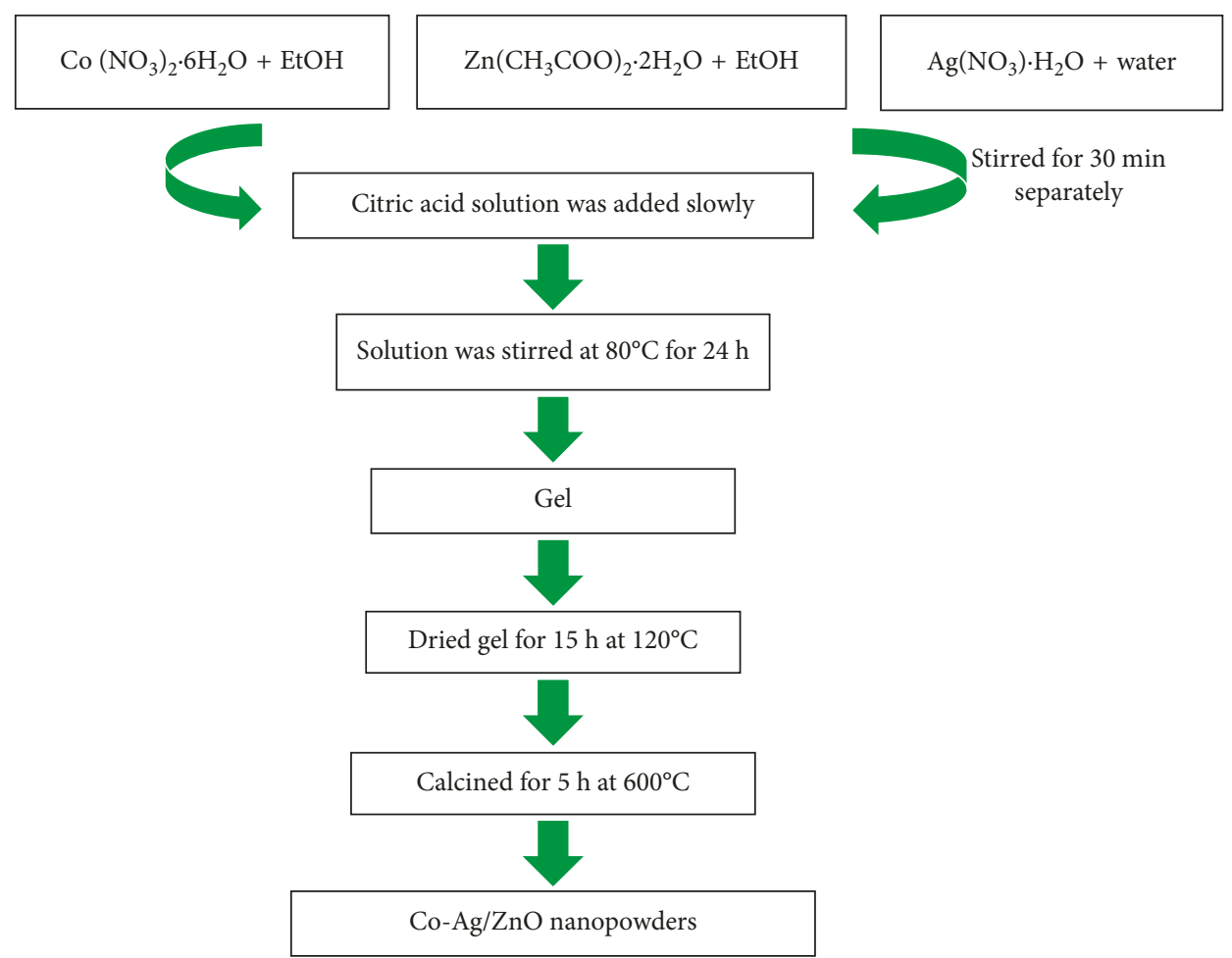

Figure 1: Flow chart for synthesis of $\mathrm{Co}-\mathrm{Ag} / \mathrm{ZnO}$ nanopowders by a sol-gel method.

measured by $\mathrm{N}_{2}$ adsorption-desorption technique using a Micromeritics analyser P/N 05098-2.0 Rev A. The stretching vibration frequency of the catalyst was recorded by FT-IR spectroscopy in the range of $400-4000 \mathrm{~cm}^{-1}$ using a Bruker vertex 70 DTGS. Spectrometer XRD measurements were performed on a XPERT-MPD Philips diffractometer using $\mathrm{Cu}-\mathrm{K} \alpha$ radiation as the $\mathrm{X}$-ray source in the $2 \theta$ range of $20^{\circ}-80^{\circ}$. The size and morphology of the microstructures were carried out on VEGA3 TESCAN microscope equipped with an energy dispersive X-ray spectrometer (EDAX TEAM).

\subsection{Preparation of the Catalyst. Pure $\mathrm{ZnO}$ nanopowders were} prepared by a sol-gel method. $\mathrm{Zn}\left(\mathrm{CH}_{3} \mathrm{COO}\right)_{2} 2 \mathrm{H}_{2} \mathrm{O}(50 \mathrm{~mL}$, $0.5 \mathrm{M}$ in ethanol) and citric acid $(50 \mathrm{~mL}, 0.5 \mathrm{M}$ in ethanol) were stirred separately for $30 \mathrm{~min}$. Then, the citric acid solution was added slowly into the solution of zinc acetate. This hydroalcoholic solution was heated at $80^{\circ} \mathrm{C}$ for $24 \mathrm{~h}$, giving an opaque white gel which was dried at $120^{\circ} \mathrm{C}$ overnight and calcined at $600^{\circ} \mathrm{C}$ for 5 hours under air to offer pure $\mathrm{ZnO}$. The same procedure was used to prepare nanopowders of $\mathrm{Zn}_{1-x-y} \mathrm{Ag}_{x} \mathrm{Co}_{y} \mathrm{O}$ by adding the needed amount of Co $\left(\mathrm{NO}_{3}\right)_{2} \cdot 6 \mathrm{H}_{2} \mathrm{O}(0.5 \mathrm{M})$ and $\mathrm{Ag}\left(\mathrm{NO}_{3}\right)(0.5 \mathrm{M})$ (Figure 1). Six samples were prepared: $\mathrm{C} 1$ (pure $\mathrm{ZnO}) ; \mathrm{C} 2$ (1\% mol Ag-doped $\mathrm{ZnO}$ ); C3 (1\% mol Co-doped $\mathrm{ZnO})$; C4 (1\% mol Co-1\% mol Ag codoped $\mathrm{ZnO})$; C5 (2.5\% mol Co-2.5\% mol Ag codoped $\mathrm{ZnO}$ ), and C6 (5\% mol Co-5\% mol Ag codoped $\mathrm{ZnO}$ ).

2.4. Catalytic Activity. The oxidation of styrene with hydrogen peroxide as the oxidant was carried out in a $50 \mathrm{~mL}$ rotaflow tube with magnetic stirring immersed in bath oil. The activity of the catalyst $\left(\mathrm{Zn}_{1-x-y} \mathrm{Ag}_{x} \mathrm{Co}_{y} \mathrm{O}\right)$ was studied varying the following parameters: doping percents of $0 \leq x \leq 0.05$ and $0 \leq y \leq 0.05, \mathrm{H}_{2} \mathrm{O}_{2}$ /styrene molar ratios from 1.1 to 3 , reaction temperatures range $\left(40^{\circ} \mathrm{C}-120^{\circ} \mathrm{C}\right)$, and the amount of the catalyst $(0.005-0.02 \mathrm{~g})$ in aprotic and protic solvents. Aliquots samples from the reaction mixture were taken at regular intervals and were monitored by gas chromatography (GC) equipped with FID using Rtx-5 capillary column. Dodecane was used as an internal standard for the quantitative analysis of the reaction products. The conversion of styrene was based on the unreacted substrate.

\section{Results and Discussion}

3.1. Characterization of the Catalysts. Figure 2 shows XRD patterns of pure $\mathrm{ZnO}$ and $\mathrm{Zn}_{1-x-y} \mathrm{Ag}_{x} \mathrm{Co}_{y} \mathrm{O}$ nanopowders calcined at $600^{\circ} \mathrm{C}$. According to pure $\mathrm{ZnO}$ reference (00-0361451), the sample corresponding to $C 3$ is highly crystallized and all diffraction peaks are well indexed to the diffraction pattern of hexagonal $\mathrm{ZnO}$ with the $\mathrm{P} 63 \mathrm{mc}$ space group. However, the $\mathrm{ZnO}$ doped with $1 \%$ mol of $\mathrm{Ag}(\mathrm{C} 2)$ revealed new peaks with weak intensities at $38.20^{\circ}$ and $44.62^{\circ}$, as it was reported by Zeferino et al. [13]. The doping concentration of $2 \%$ to $10 \%$ mole of Co-Ag (C5 and C6) can lead to the formation of $\mathrm{Co}_{3} \mathrm{O}_{4}$ with a corresponding trace at $64.66^{\circ}[14]$.

Table 1 summarizes the position and the width at midheight (FWHM) of the main peaks, along with the lattice parameter values calculated from the XRD patterns of the pure and codoped $\mathrm{ZnO}$ nanopowders. The incorporation of $\mathrm{Co}-\mathrm{Ag}$ on $\mathrm{ZnO}$ results in the decrease of the FWHM, 


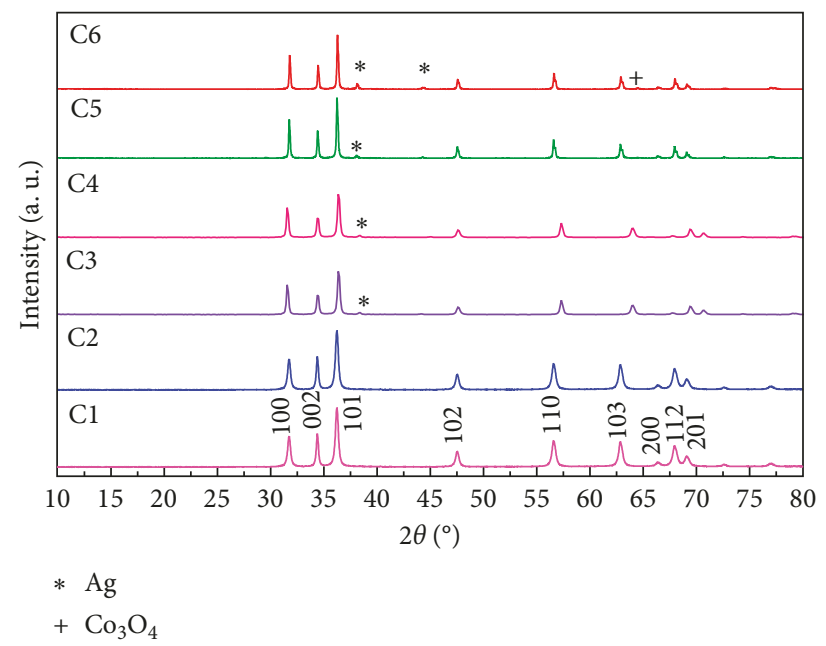

FIGURE 2: XRD patterns of $\mathrm{Zn}_{1-x-y} \mathrm{Ag}_{x} \mathrm{Co}_{y} \mathrm{O}$.

Table 1: Position, FWHM, and the lattice parameters of $\mathrm{Zn}_{1-x-y} \mathrm{Ag}_{x} \mathrm{Co}_{y} \mathrm{O}$ nanopowders.

\begin{tabular}{|c|c|c|c|c|}
\hline \multirow{2}{*}{ Nominal Ag-Co concentration } & \multirow{2}{*}{ Position of the (101) peak } & \multirow{2}{*}{ FWHM (degree) } & \multicolumn{2}{|c|}{ Lattice parameters $(\AA)$} \\
\hline & & & $a$ & $c$ \\
\hline $0 \% \mathrm{~mol}$ & 36.2583 & 0.2134 & 3.2498 & 5.2066 \\
\hline $1 \% \mathrm{~mol} \mathrm{Ag}$ & 36.3177 & 0.082 & 3.24509 & 5.18829 \\
\hline $1 \% \mathrm{~mol} \mathrm{Co}$ & 36.1927 & 0.325 & 3.25037 & 5.19644 \\
\hline $1 \% \mathrm{~mol} \mathrm{Ag}-1 \% \mathrm{~mol} \mathrm{Co}$ & 38.279 & 0.200 & 3.28825 & 5.23984 \\
\hline $2.5 \% \mathrm{~mol} \mathrm{Ag}-2.5 \% \mathrm{~mol} \mathrm{Co}$ & 36.4427 & 0.078 & 3.24454 & 5.19797 \\
\hline $5 \% \mathrm{~mol} \mathrm{Ag}-5 \% \mathrm{~mol} \mathrm{Co}$ & 36.3177 & 0.075 & 3.24016 & 5.21778 \\
\hline
\end{tabular}

indicating an increase in crystallinity. A shift position of the diffraction peak (002) could be attributed to the incorporation of $\mathrm{Ag}^{+}$and $\mathrm{Co}^{2+}$ ions in the $\mathrm{ZnO}$ lattice sites. As it was shown earlier, $\mathrm{Ag}^{+}$ions in the $\mathrm{ZnO}$ lattice sites, probably substitute $\mathrm{Zn}^{2+}$ ions [13].

On the other hand, the peaks associated with the cobalt oxide or cobalt hydroxide phases such as $\mathrm{CoO}$ or $\mathrm{Co}(\mathrm{OH})_{2}$ were not detected as shown in the XRD patterns (Figure 2). According to Wojnarowicz et al. [15], some precipitation of $\mathrm{Co}_{3} \mathrm{O}_{4}$ was observed in the XRD investigation for the $10 \%$ mol Co-Ag sample in synthetic air.

TG/DTG curves of the prepared materials (supplementary data 2) reveal one thermal event at $162^{\circ} \mathrm{C}$ attributed to the loss of crystal water from the catalyst (2.42 wt.\%).

To investigate the specific areas and the porous nature of the C4 nanopowders, Brunauer-Emmett-Teller (BET) gas sorption measurements were performed. The nitrogen adsorption-desorption isotherm and the pore size distribution plots of the C4 sample are shown in supplementary data 3. The sample corresponds to type IV and V isotherm and type $\mathrm{H} 3$ hysteresis loop appearing which is attributed to the predominance of mesopores [16]. The determined surface area of the C4 sample was $5.90 \mathrm{~m}^{2} / \mathrm{g}$, and the calculated $\mathrm{BJH}$ pores size was $5.42 \mathrm{~nm}$.

FT-IR spectrum (supplementary data 4) of C4 nanopowder shows a strange band at $600 \mathrm{~cm}^{-1}$ and a relatively weak band at $500 \mathrm{~cm}^{-1}$ which could be assigned to the stretching modes of $\mathrm{Zn}-\mathrm{O}$ [17]. The bands in the range
910-1537 $\mathrm{cm}^{-1}$ may be attributed to the residual $\mathrm{NO}_{3}{ }^{-}$ions [18]. A weak band at $2375 \mathrm{~cm}^{-1}$ is attributed to the $\mathrm{CO}_{2}$ present in air. The bands at $3400 \mathrm{~cm}^{-1}$ and $1630 \mathrm{~cm}^{-1}$ correspond to the stretching of hydroxyl groups due to the adsorption of water on the particles' surface [19].

The scanning electron microscopy (SEM) of the undoped and the Ag-Co codoped $\mathrm{ZnO}$ nanopowders are shown in Figure 3. Ag and Co do not bring significant change in the morphology. The EDX results confirmed that the products consist of zinc, cobalt, and silver elements in $\mathrm{ZnO}$ nanopowders, which are in good agreement with XRD patterns.

3.2. Catalytic Experiments. The oxidation reaction of styrene is influenced by several parameters. In an attempt to find out the suitable reaction conditions providing an optimum of conversion and yield, effects of different reaction conditions have been carried out.

3.2.1. Effect of Catalyst Loading. As shown in Table 2, when the loading amount of Co and $\mathrm{Ag}$ was increased from 2 to $10 \% \mathrm{~mol}$, there was an obvious increase in styrene conversion from 61 to $80 \%$ (entries $5-7$ ), but the selectivity of benzaldehyde decreases for more than $2 \%$ mol (entries 6-7). However, with $1 \%$ mol, either with Co or Ag, a similar result was obtained (entries 3-4). In the presence of pure $\mathrm{ZnO}$ or in the absence of the catalyst, no significant conversion was observed. 

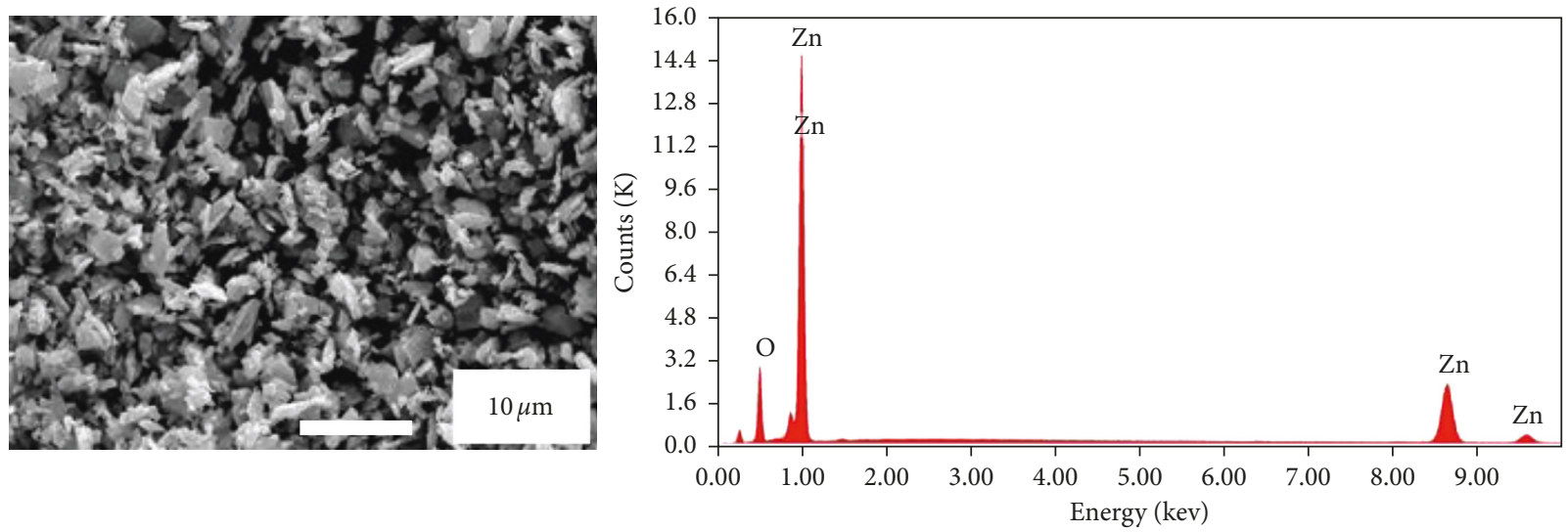

(a)
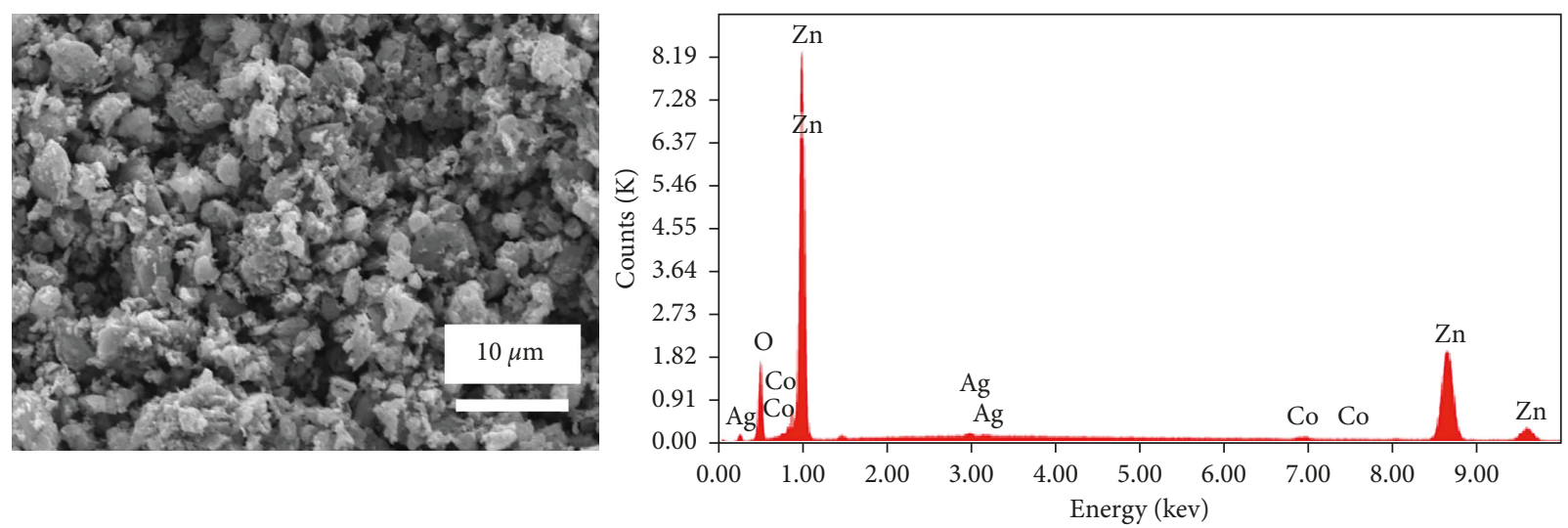

(b)
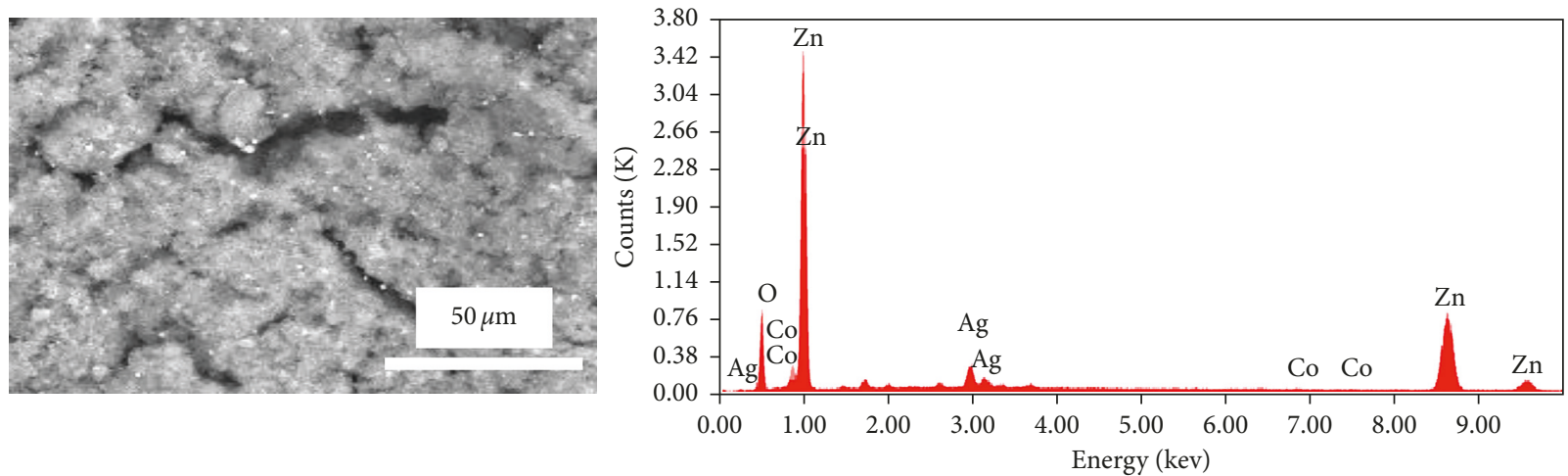

(c)

FIGURE 3: SEM images and EDX spectra of (a) C1, (b) C4 before used, and (c) C4 after the 4th cycles.

3.2.2. Effect of Catalyst Amount. To investigate the catalyst amount effect on the oxidation reaction, different amounts of the C4 catalyst have been studied. As shown in Table 2, the optimal catalyst amount was found to be $0.02 \mathrm{~g}$ with high selectivity of benzaldehyde (95\%).

3.2.3. Effect of the Reaction Time. In order to shed more light on this point, a kinetic study was carried out with $0.02 \mathrm{~g}$ of C4 catalyst using GC to determine the conversion and product distribution (Figure 4). As depicted, the evolution of styrene versus time shows that benzaldehyde was formed as the major product. This compound reached a maximum after 24 hours with $61 \%$ in conversion and $95 \%$ in selectivity.

3.2.4. Effect of Molar Ratio $\mathrm{H}_{2} \mathrm{O}_{2}$ /Styrene. The catalytic oxidation of styrene using the $\mathrm{C} 4$ catalyst was performed by varying the molar ratio of the $\mathrm{H}_{2} \mathrm{O}_{2}$ /styrene. The increase in molar ratio from $1: 1$ to $1: 2.5$ resulted in a significant increase in the conversion. The yield of benzaldehyde increased from $57 \%$ to $72 \% \mathrm{~mol}$. However, the selectivity of benzaldehyde slightly decreases (Table 3 ). 
TABLE 2: Effect of the catalyst's amount and loading.

\begin{tabular}{lccccc}
\hline Entry & Catalyst & Amount of catalyst $(\mathrm{g})$ & Styrene conversion & \multicolumn{2}{c}{ Yield $^{\mathrm{a}}(\% \mathrm{~mol})$} \\
Acetophenone
\end{tabular}

Reaction conditions: $\mathrm{H}_{2} \mathrm{O}_{2} /$ styrene, 1 ; temperature, $80^{\circ} \mathrm{C}$; solvent, acetonitrile; reaction time, $24 \mathrm{~h}$; ${ }^{\mathrm{a}}$ yields determined by GC using dodecane as an internal standard.

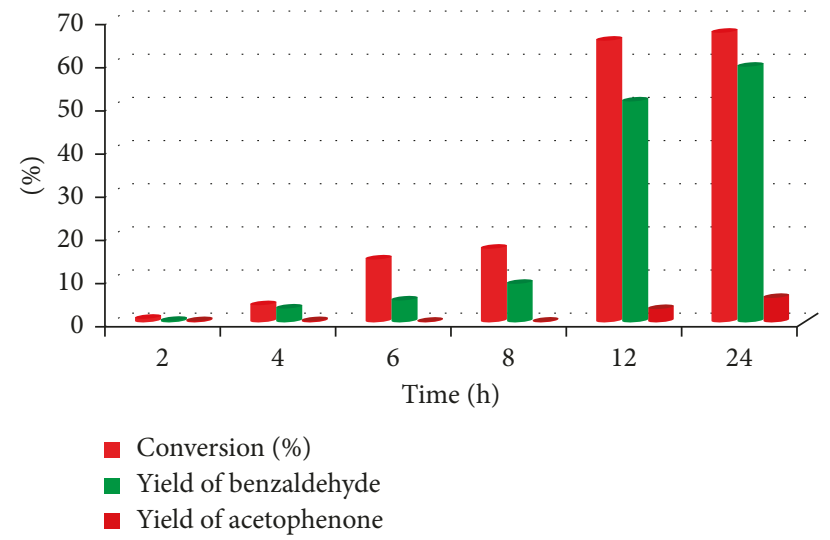

FIGURE 4: Effect of reaction time on the oxidation of styrene. Reaction conditions: $\mathrm{H}_{2} \mathrm{O}_{2}$ /styrene, 1 ; temperature, $80^{\circ} \mathrm{C}$; solvent, acetonitrile. Yields are determined by GC using dodecane as an internal standard.

TABLE 3: Effect of styrene, $\mathrm{H}_{2} \mathrm{O}_{2}$ molar ratio, temperature, and solvent.

\begin{tabular}{|c|c|c|c|c|c|c|}
\hline \multirow{2}{*}{ Entry } & \multirow{2}{*}{$\mathrm{H}_{2} \mathrm{O}_{2} /$ Styrene } & \multirow{2}{*}{ Solvant } & \multirow{2}{*}{ Temperature $\left({ }^{\circ} \mathrm{C}\right)$} & \multirow{2}{*}{ Styrene conversion } & \multicolumn{2}{|c|}{ Yield $^{\mathrm{a}}(\% \mathrm{~mol})$} \\
\hline & & & & & Benzaldehyde & Acetophenone \\
\hline 1 & 1.1 & Acetonitrile & 80 & 61 & 57 & 3 \\
\hline 2 & 1.5 & Acetonitrile & 80 & 66 & 62 & 3 \\
\hline 3 & 2 & Acetonitrile & 80 & 70 & 67 & 3 \\
\hline 4 & 2.5 & Acetonitrile & 80 & 81 & 72 & 3.5 \\
\hline 5 & 3 & Acetonitrile & 80 & 95 & 73 & 5 \\
\hline 6 & 2.5 & Acetonitrile & 40 & 10 & 10 & 0 \\
\hline 7 & 2.5 & Acetonitrile & 70 & 50 & 50 & 0 \\
\hline 8 & 2.5 & Acetonitrile & 100 & 94 & 60 & 4 \\
\hline 9 & 2.5 & Acetonitrile & 120 & 98 & 50 & 9 \\
\hline 10 & 2.5 & Acetone & 80 & 90 & 77 & 12 \\
\hline 11 & 2.5 & Water & 80 & 12 & 12 & 0 \\
\hline 12 & 2.5 & Methanol & 80 & 75 & 59 & 6 \\
\hline 13 & 2.5 & Ethanol & 80 & 50 & 31 & 7 \\
\hline
\end{tabular}

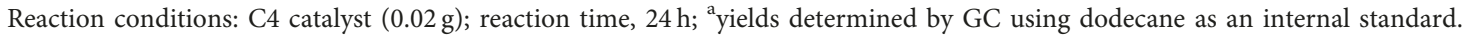

3.2.5. Effect of Reaction Temperature. Table 3 depicts the influence of reaction temperature on the oxidation of styrene catalyzed by the $\mathrm{C} 4$ catalyst. The increase of the temperature from $40^{\circ} \mathrm{C}$ to $120^{\circ} \mathrm{C}$ results in the increased conversion from 10 to 98 , indicating that the styrene conversion has a strong dependency on the reaction temperature. Hence, at high temperature, the benzaldehyde selectivity decreases in competition with the formation of acetophenone and other products. This confirms that the cleavage of $\mathrm{C}=\mathrm{C}$ bond is greater at lower temperatures and epoxidation participates more favorably against $\mathrm{C}=\mathrm{C}$ cleavage to high temperatures $[20,21]$. 


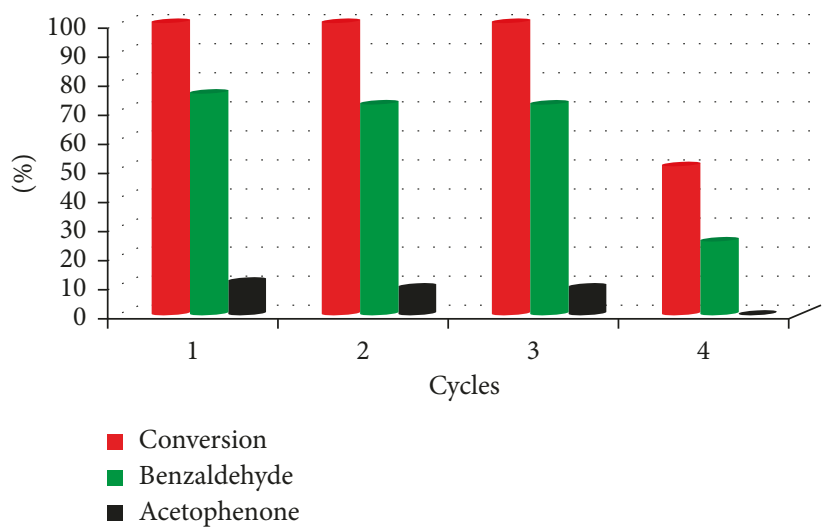

FIgURE 5: Reusability of the catalyst in oxidation of styrene. Reaction conditions: C4 catalyst $(0.02 \mathrm{~g}) ; \mathrm{H}_{2} \mathrm{O}_{2} /$ styrene, 2.5 , temperature, $80^{\circ} \mathrm{C}$; solvent, acetone; reaction time, $24 \mathrm{~h}$. Yields are determined by GC using dodecane as an internal standard.

3.2.6. Effect of the Solvent. An examination of the effects of a variety of protic and aprotic solvents on the model reaction using C4 as the catalyst has been carried out (Table 3).

According to Kumar [22], aprotic solvents are more favorable for the styrene oxidation than protic ones. The selectivity towards benzaldehyde with respect to percentage yield is in the following order: $\mathrm{CH}_{3} \mathrm{CN}>\mathrm{CH}_{3} \mathrm{COCH}_{3}>$ $\mathrm{CH}_{3} \mathrm{OH}>\mathrm{C}_{2} \mathrm{H}_{5} \mathrm{OH}>\mathrm{H}_{2} \mathrm{O}$. The styrene conversion in acetone, methanol, ethanol, and water is, respectively, equal to $90 \% \mathrm{~mol}, 75 \% \mathrm{~mol}, 50 \% \mathrm{~mol}$, and $12 \% \mathrm{~mol}$, with $77 \% \mathrm{~mol}$, $59 \% \mathrm{~mol}, 31 \% \mathrm{~mol}$, and $12 \% \mathrm{~mol}$ yield of benzaldehyde, respectively. Among the solvents, acetonitrile appears to be the best one (entry 4).

3.2.7. Recycling of Catalyst. To investigate the reusability of $\mathrm{C} 4$, the catalytic activity of this catalyst was evaluated in four consecutive cycles (Figure 5). Before reusing the catalyst, it was separated from the reaction mixture by filtration, washed with water, and finally dried at $200^{\circ} \mathrm{C}$ for 2 hours. As shown in Figure 5, the catalyst still exhibits a good catalytic activity in the first three reuse cycles. However, a noticeable drop in styrene conversion was observed after the fourth consecutive run due to agglomerated particles.

SEM image of C4 before and after four cycles of oxidation has been studied (Table 4). Before the catalytic test, SEM image of the Ag-Co codoped $\mathrm{ZnO}$ shows relatively dispersed nanoparticles (Figure 3(b)). However, SEM morphology of the catalyst after four cycles of oxidation showed agglomerated particles with the presence of smaller single particles (Figure 3(c)). Even by SEM, the physical change of the matrix is well visible due to probable decomposition during the reaction. In fact, EDX on various regions of the catalyst after 4 cycles confirmed the presence of Co and Ag elements without any significant variation. The analysis indicates a predominance of oxygen species, which comes mainly from the oxidation of Co and Ag species, leading to the deactivation of the catalyst.

\section{Conclusion}

In this study, the C4 catalyst was prepared by a sol-gel method, and its catalytic activity was investigated in the
TABLE 4: EDX analysis of C4 before using and at the 1st, 2nd, 3rd, and 4 th cycles.

\begin{tabular}{llcc}
\hline Elements & & Wt.\% & Atomic \% \\
\hline \multirow{4}{*}{ As-prepared catalyst } & OK & 14.73 & 41.58 \\
& AgL & 1.88 & 0.76 \\
& CoK & 0.42 & 0.32 \\
& ZnK & 82.96 & 57.31 \\
\hline \multirow{4}{*}{ 1st cycle } & OK & 18.05 & 47.58 \\
& AgL & 1.97 & 0.76 \\
& CoK & 0.45 & 0.32 \\
2nd cycle & ZnK & 79.54 & 51.31 \\
& OK & 20.80 & 52.01 \\
& AgL & 2.08 & 0.77 \\
& CoK & 0.44 & 0.30 \\
3rd cycle & ZnK & 76.68 & 46.92 \\
& OK & 25.54 & 58.63 \\
& AgL & 2.26 & 0.77 \\
& CoK & 0.43 & 0.27 \\
\multirow{3}{*}{ 4th cycle } & ZnK & 71.77 & 40.32 \\
& OK & 31.36 & 65.43 \\
& AgL & 2.49 & 0.77 \\
& CoK & 0.36 & 0.20 \\
& ZnK & 65.73 & 33.59 \\
\hline
\end{tabular}

oxidation of styrene. Among all the catalysts examined, the C4 catalyst exhibited the best activity and provided $76 \%$ yield of benzaldehyde in the presence of $\mathrm{H}_{2} \mathrm{O}_{2}$ as an oxidant after 24 hours. The optimum reaction conditions was acetonitrile, temperature reaction $80^{\circ} \mathrm{C}, \mathrm{H}_{2} \mathrm{O}_{2}$ /styrene molar ratio equal to 2.5 , catalyst loading of $1 \% \mathrm{~mol} \mathrm{Ag}-1 \% \mathrm{~mol} \mathrm{Co}$, and the catalyst amount of $0.02 \mathrm{~g}$. Under the optimized conditions, the Co-Ag codoped $\mathrm{ZnO}$ shows a high degree of efficiency and selectivity towards the oxidation reactions.

\section{Conflicts of Interest}

The authors declare that they have no conflicts of interest.

\section{Supplementary Materials}

General scheme, SEM images, EDX, FT-IR spectra, and other analytical data are available free of charge via the 
Internet in the Electronic Supporting Information (ESI). Supplementary data 1: catalytic oxidation of styrene. Supplementary data 2: TG and DTG curves of C4. Supplementary data 3: N2 adsorption-desorption isotherm and BJH pore diameter distribution of C4. Supplementary data 4: FT-IR spectrum of C4. Supplementary data 5: SEM images and EDX spectra of (a) C1, (b) C2, (c) C3, (d) C4, (e) C5, (f) C6, (g) 1st cycle, (h) 2nd cycle, (i) 3th cycle, and (j) 4th cycle of the reused catalyst. (Supplementary Materials)

\section{References}

[1] N. Ma, "Selective oxidation of styrene over nanosized spineltype $\mathrm{Mg}_{x} \mathrm{Fe}_{3-x} \mathrm{O}_{4}$ complex oxide catalysts," Applied Catalysis A: General, vol. 251, no. 1, pp. 39-47, 2003.

[2] J. Liu, F. Wang, Z. Gu, and X. Xu, "Vanadium phosphorus oxide catalyst modified by silver doping for mild oxidation of styrene to benzaldehyde," Chemical Engineering Journal, vol. 151, no. 1-3, pp. 319-323, 2009.

[3] K. S. Suslick, "Sonochemistry," in Kirk-Othmer Encyclopedia of Chemical Technology, vol. 26, John Wiley \& Sons, New York, NY, USA, 4th edition, 1998.

[4] V. R. Choudhary and D. K. Dumbre, "Solvent-free selective oxidation of benzyl alcohol to benzaldehyde by tert-butyl hydroperoxide over $\mathrm{U}_{3} \mathrm{O}_{8}$-supported nano-gold catalysts," Applied Catalysis A: General, vol. 375, no. 2, pp. 252-257, 2010.

[5] X. Zhu, R. Shen, and L. Zhang, "Catalytic oxidation of styrene to benzaldehyde over a copper Schiff-base/SBA-15 catalyst," Chinese Journal of Catalysis, vol. 35, no. 10, pp. 1716-1726, 2014.

[6] A. Suresh Kumar, B. Thulasiram, S. Bala Laxmi, V. S. Rawat, and B. Sreedhar, "Magnetic $\mathrm{CuFe}_{2} \mathrm{O}_{4}$ nanoparticles: a retrievable catalyst for oxidative amidation of aldehydes with amine hydrochloride salts," Tetrahedron, vol. 70, no. 36, pp. 6059-6067, 2014.

[7] V. Parvulescu, C. Constantin, and B. L. Su, "Liquid phase oxidation of aromatic hydrocarbons using highly ordered $\mathrm{Nb}$ and NbCo-MCM-41 nanoreactors," Journal of Molecular Catalysis A:Chemical, vol. 202, no. 1-2, pp. 171-178, 2003.

[8] D. Gao and Q. Gao, "Selective oxidation of styrene to benzaldehyde over VSB-5 and isomorphously substituted cobalt VSB-5," Catalysis Communications, vol. 8, no. 4, pp. 681-685, 2007.

[9] L. B. Pierella, C. Saux, S. C. Caglieri, H. R. Bertorello, and P. G. Bercoff, "Catalytic activity and magnetic properties of Co-ZSM-5 zeolites prepared by different methods," Applied Catalysis A: General, vol. 347, no. 1, pp. 55-61, 2008.

[10] N. T. Thao and H. H. Trung, "Selective oxidation of styrene over Mg-Co-Al hydrotalcite like-catalysts using air as oxidant," Catalysis Communications, vol. 45, pp. 153-157, 2014.

[11] Y. Long, Z. Zhao, L. Wu et al., "Distinctive ligand effects of functionalized magnetic microparticles immobilizing palladium acetate as heterogeneous coordination catalysts for selective oxidation of styrene to acetophenone," Molecular Catalysis, vol. 433, pp. 291-300, 2017.

[12] N. Li, Y. Gao, X. Zhang, Z. Yu, L. Shi, and Q. Sun, "Oxidation of styrene to benzaldehyde by p-toluenesulfonic acid using hydrogen peroxide in the presence of activated carbon," Chinese Journal of Catalysis, vol. 36, no. 5, pp. 721-727, 2015.

[13] R. S. Zeferino, M. B. Flores, and U. Pal, "Photoluminescence and Raman scattering in Ag-doped ZnO nanoparticles," Journal of Applied Physics, vol. 109, no. 1, p. 014308, 2011.
[14] H. Yang and S. Nie, "Preparation and characterization of Codoped ZnO nanomaterials," Materials Chemistry and Physics, vol. 114, no. 1, pp. 279-282, 2009.

[15] J. Wojnarowicz, S. Kusnieruk, T. Chudoba et al., "Paramagnetism of cobalt-doped $\mathrm{ZnO}$ nanoparticles obtained by microwave solvothermal synthesis," Beilstein Journal of Nanotechnology, vol. 6, pp. 1957-1969, 2015.

[16] Z. A. Alothman, "A review: fundamental aspects of silicate mesoporous materials," Materials, vol. 5, no. 12, pp. 28742902, 2012.

[17] C. Pholnak, C. Sirisathitkul, S. Suwanboon, and D. J. Harding, "Effects of precursor concentration and reaction time on sonochemically synthesized $\mathrm{ZnO}$ nanoparticles," Materals Research, vol. 17, no. 2, pp. 405-411, 2014.

[18] M. Viertelhaus, E. Taylor, L. Kloo, I. Gameson, and P. Anderson, "Silver nitrate in silver zeolite A: threedimensional incommensurate guest ordering in a zeolite framework," Dalton Transactions, vol. 19, pp. 2368-2373, 2006.

[19] Y.-M. Hao, S.-Y. Lou, S.-M. Zhou, R.-J. Yuan, G.-Y. Zhu, and N. Li, "Structural, optical, and magnetic studies of manganese-doped zinc oxide hierarchical microspheres by self-assembly of nanoparticles," Nanoscale Research Letters, vol. 7, no. 1, p. 100, 2012.

[20] C. Saux and L. B. Pierella, "Studies on styrene selective oxidation to benzaldehyde catalyzed by Cr-ZSM-5: Reaction parameters effects and kinetics," Applied Catalysis A: General, vol. 400, no. 1-2, pp. 117-121, 2011.

[21] M. V. Cagnoli, S. G. Casuscelli, A. M. Alvarez et al., "clean limonene epoxidation using Ti-MCM-41 catalyst," Applied Catalysis A: General, vol. 287, no. 2, pp. 227-235, 2005.

[22] S. Kumar, "Epoxidation of styrene over a titanium silicate molecular sieve TS1 using dilute $\mathrm{H}_{2} \mathrm{O}_{2}$ as oxidizing agent," Journal of Catalysis, vol. 156, no. 1, pp. 163-166, 1995. 


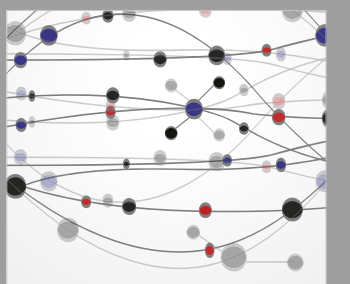

The Scientific World Journal
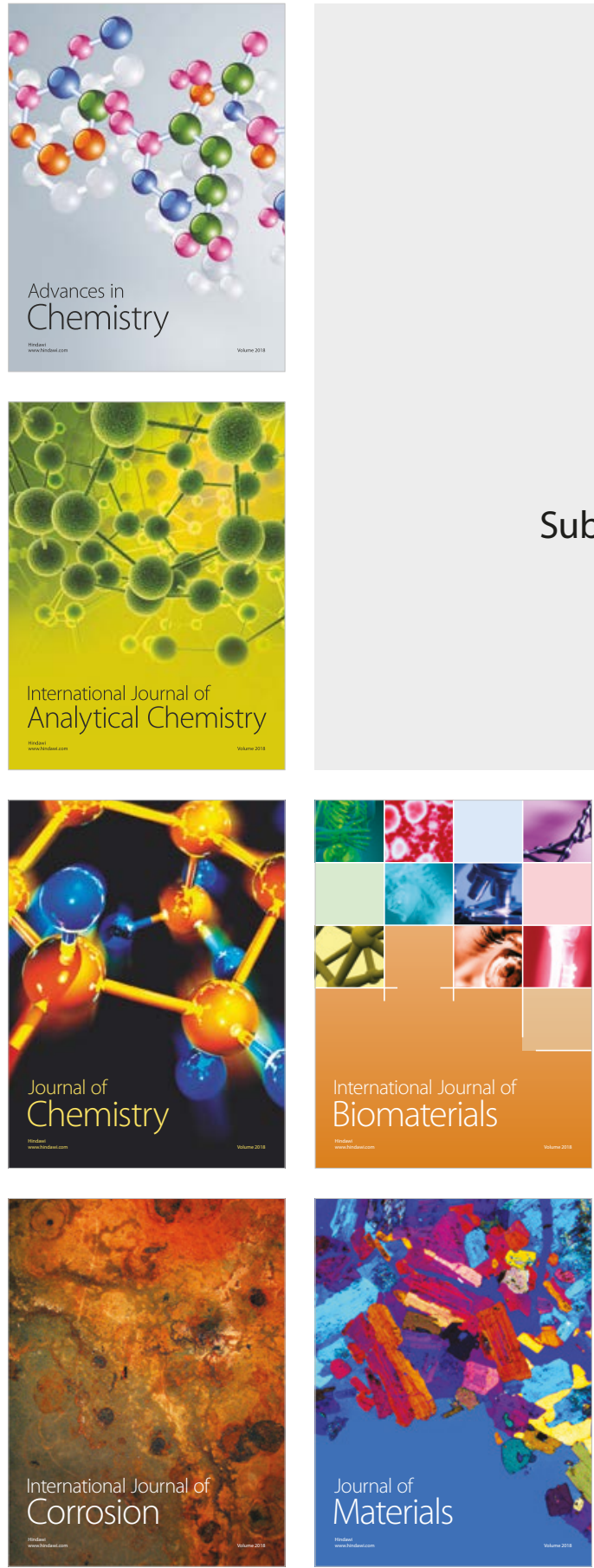

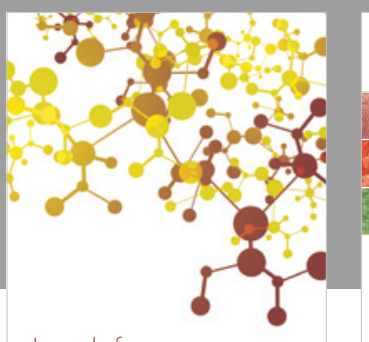

Journal of

Applied Chemistry
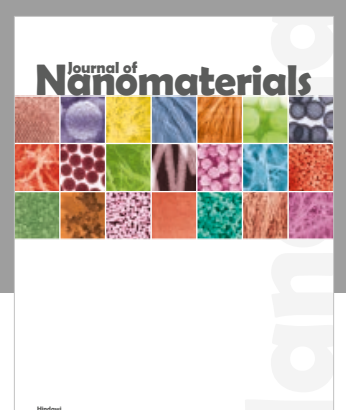

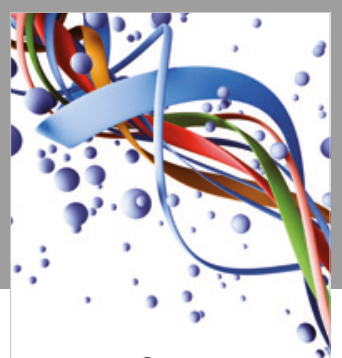

Scientifica

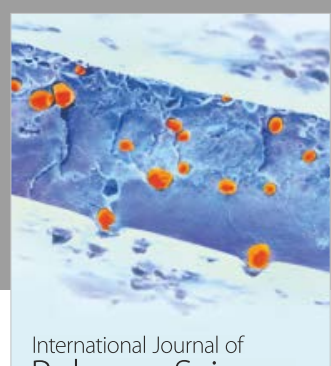

Polymer Science

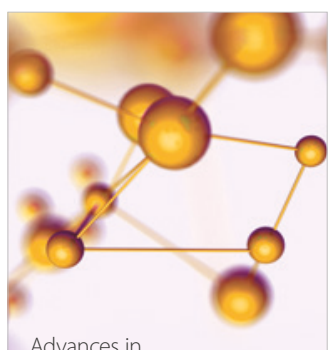

Physical Chemistry
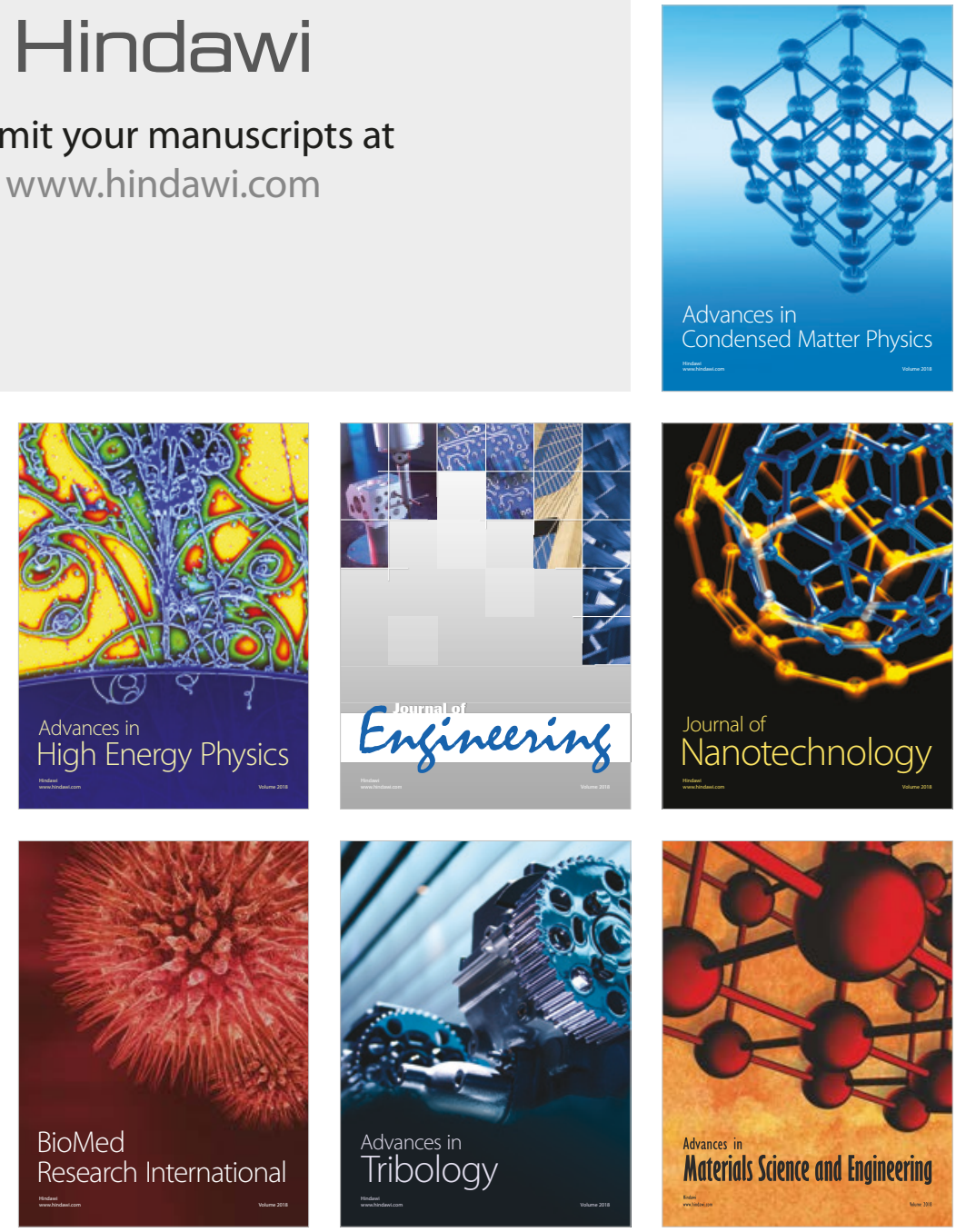